\title{
SALÁRIO MÍNIMO E PREÇOS COMO DETERMINANTES DE COMPLEMENTARIDADE EM CONURBAÇÕES BINACIONAIS
}

\author{
PRICES AND MINIMUM WAGE AS COMPLEMENTARY \\ DETERMINING FACTORS IN BINATIONAL CONURBATIONS
}

SALARIO MÍNIMO Y PRECIOS COMO FACTORES DETERMINANTES DE
LA COMPLEMENTARIEDAD EN LAS CONURBACIONES BINACIONALES

Lisandra Pereira Lamoso - Universidade Federal de Grande Dourados -

Dourados - Mato Grosso do Sul - Brasil

lisandralamoso@ufgd.edu.br

\begin{abstract}
Resumo
A taxa de câmbio é uma informação relevante para compreensão da integração comercial nas cidades conurbadas binacionais ou cidades-gêmeas. Discutimos outro elemento para compreender os processos de integração e complementaridade comercial. 0 valor do salário mínimo e seu poder de compra em cada lado da fronteira, nesse caso, a conurbação de Pedro Juan Caballero (Departamento de Amambay - Paraguai) e Ponta Porã (Mato Grosso do Sul - Brasil). A pesquisa realizou levantamento de preços em janeiro de 2013 e outubro de 2015 para confirmar a hipótese de que a conurbação tem um movimento pendular e orgânico que transcende 0 efeito do dólar como moeda de compra. 0 dólar é elemento estruturador do turismo de compras, mas não do cotidiano das cidades-gêmeas.
\end{abstract}

Palavras-chave: cidades conurbadas binacionais, fronteira, cidades-gêmeas, práticas de fronteirização.

\begin{abstract}
The exchange rate is a significant information for the understanding of commercial integration in the binational conurbated cities or twin cities. This paper discusses another element to comprehend the processes of integration and commercial complementarity: the minimum wage value and its purchasing power on either side of the border. In this case, the conurbation between Pedro Juan Caballero (the capital of Amambay department - Paraguay) and Ponta Porã (in the state of Mato Grosso do Sul State - Brazil) is studied. The research conducted a survey of prices on two dates, January 2013 and October 2015, to confirm the hypothesis that the conurbation has a pendular and organic movement that transcends the effect of the dollar as a currency of acquisition. The dollar is particularly an structural element of the shopping tourism and not of everyday life in the twin cities, which has in the concept of place its prominence as an explanatory element. Keywords: binational conurbated cities, borders, twin cities, practices of bordering.
\end{abstract}

\section{Resumen}

La tasa de cambio es una información importante para la comprensión de la integración comercial en las ciudades conurbadas binacionales o ciudades-gemelas. En este artículo, se discute otro elemento para entender los procesos de integración y complementariedad comercial. El valor del salario mínimo y su poder adquisitivo a uno y otro lado de la frontera, en este caso, la conurbación de Pedro Juan Caballero (Departamento de Amambay - Paraguay) y Ponta Porã (Mato Grosso do Sul - Brasil). La investigación realizó levantamiento de precios en enero de 2013 y octubre de 2015 para confirmar la hipótesis de que la conurbación tiene un movimiento pendular y orgánico que trasciende el efecto del dólar como moneda de compra. El dólar es elemento estructurador del turismo de compras, pero no del cotidiano de las ciudades-gemelas.

Palabras clave: ciudades conurbadas binacionales, frontera, ciudades-gemelas, prácticas de fronterización. 


\section{Introdução}

Os processos de integração fronteiriça retornaram à agenda das políticas públicas brasileiras no início do século XXI, repercutindo em um maior número de pesquisas acadêmicas que se dedicam a compreender as dinâmicas socioespaciais nos espaços de fronteira. Nesse contexto, voltamos nosso olhar para a fronteira de Mato Grosso do Sul com Paraguai, na conurbação Ponta Porã (Mato Grosso do Sul) e Pedro Juan Caballero (Departamento de Amambay).

No âmbito conceitual, é difícil pensar Fronteira enquanto uma "zona de significados claramente demarcada" (Albuquerque, 2012, p.72). Compreender a fronteira pressupõe interpretar, para além da paisagem divisória entre distintas soberanias nacionais, o cotidiano como uma construção em relação à alteridade do outro. A polissemia do conceito "Fronteira" está explorada por vários autores, entre eles Albuquerque (2012) e Machado (2005) que, respectivamente, discutem multiplicidade/ paradoxos e a fronteira como integração/complementaridade. Algumas adjetivações surgem com o intuito de complementar o arcabouço teórico que possibilita uma, entre várias, interpretações do real. É este o caso da noção de "fronteirização", utilizada para a leitura de períodos mais longos de sedimentação das ações estatais e dos agentes locais, em constante mutação. ${ }^{1}$ São materialidades e relações que ganham concretude no controle do ir e vir, da separação entre «nós e outros», no controle da acessibilidade. Fronteirização, para Benedetti (2012, p. 21):

designa al conjunto de objetos y acciones que el poder central va estableciendo, generalmente cerca del límite pero no inevitablemente, con la intención de controlar la accesibilidad. Briones e Del Cairo (2015, p.15) exploram a noção de "práticas de fronteirização", definindo-as como "las diversas maneras en que colectivos sociales marcan un adentro y un afuera, que encuentra un correlato en la diferenciación nosotros/otros. ${ }^{2}$

A noção de "práticas de fronteirização" é útil quando associamos à definição de fronteirização como "procesos históricos a través de los cuales los diversos elementos de la fronteira son construídos por poderes centrales y por populaciones locales.”3 (Grimsom, 2003, p. 43). A construção de acessibilidades e controles confere um protagonismo aos marcos regulatórios e normativos, priorizando o cuidado com os aparatos fixos de 
inibição dos fluxos. Não há, no entanto, estudos sobre os preços e o valor do salário mínimo como mediadores de práticas de fronteirização. Nosso ponto de partida foi a constatação de que do lado brasileiro (Ponta Porã), as motocicletas que não possuíam placas de identificação foram impedidas de circular (conforme as normas nacionais, os veículos devem possuir placas e estarem quites com as obrigações legais). Com essa proibição, alguns setores do comércio varejista de Ponta Porã tiveram o movimento reduzido, queda nas vendas pela falta do consumidor paraguaio que se deslocava com seus próprios meios de transporte - as motocicletas e sem o uso do capacete (acessório obrigatório no Brasil). A partir de então, voltamos nossa atenção para compreender a complementaridade na conurbação como algo que pode ser mediado não apenas pela taxa de câmbio relativa ao dólar, mas, principalmente, pelo ir e vir no comércio varejista, pela população residente nas duas cidades. O passo seguinte foi considerar que esse movimento de comprar mercadorias no comércio do país vizinho sofre direta influência da combinação de dois fatores: o poder aquisitivo conferido pelo salário mínimo e o preço das mercadorias.

Nosso objetivo é compreender como salário mínimo e preços interferem na complementaridade comercial que existe na conurbação selecionada. Partimos da hipótese que a cotação das moedas (guarani e real) é um dado, uma informação, que altera a direção dos fluxos de compras e pode construir uma relação de fortalecimento da complementaridade comercial pelo compartilhamento de necessidades específicas, para além do turismo de compras que é determinado pela taxa de câmbio e tem no turista seu principal agente. O que justifica essa formulação é a necessidade de confirmar que o protagonismo conferido ao turismo de compras na economia da conurbação invisibiliza relações de troca mais orgânicas, que transcendem o movimento turístico de brasileiros para o lado paraguaio, em busca de produtos importados. O espaço social da conurbação Ponta Porã e Pedro Juan Caballero (PP/PJC) tem sua construção amparada em uma complementaridade econômica, social e cultural historicamente mediada pelo cotidiano da população fronteiriça. O turismo de compras, afetado pela variação cambial, altera o sentido do fluxo, mas não elimina o processo de acumulação, que passa a se dar na esfera mercantil do comércio varejista, ora do lado brasileiro, ora do lado paraguaio.

No processo de investigação, definimos algumas noções, de forma a oferecer clareza quanto aos pressupostos teóricos e pavimentar canais de comunicação interdisciplinares. Adotamos a noção de cidades conurbadas 
binacionais, "rugosidades" (Santos, 1990), equivalência das moedas. A revisão bibliográfica foi complementada com trabalho de campo que levantou preços de mercadorias em janeiro de 2013 e em outubro de 2015 (com dólar valorizado em relação ao real), para empiricizar a equivalência das moedas binacionais.

Cidades conurbadas binacionais ou cidades-gêmeas

Conforme os estudos sobre fronteiras se desenvolviam, um conjunto de definições foi elaborado por diferentes autores, com denominações diferentes para as mesmas condições. Optamos por elencar a definição de cidades conurbadas binacionais, concordando com Bento (2014, p.110), para quem "nem todas as cidades-gêmeas são cidades conurbadas (PP/PJC), mas todas as cidades conurbadas são gêmeas», considerando que, nesse caso, não há acidentes geográficos nem controle de pessoas e mercadorias na linha internacional que as separa, além de compartilharem a mesma malha urbana (Bento, 2014).

A portaria número 125, de 21 de março de 2014, do Ministério da Integração Nacional, elencou cinco cidades-gêmeas para o Estado de Mato Grosso do Sul. São elas: Bela Vista (MS) com Bella Vista; Ponta Porã (MS) com Pedro Juan Caballero; Coronel Sapucaia (MS) com Capitán Bado; Paranhos com Ypeju e Mundo Novo (MS) com Salto del Guayra, todos os pares são cidades paraguaias. Desse conjunto de cidades-gêmeas, apenas Ponta Porã e Pedro Juan Caballero (PP/PJC) são conurbações, do ponto de vista da legalidade jurídica. (Ministério da Integração Regional, 2014)

Benedetti (2014), em um esforço de esquematização, elaborou uma figura que apresenta os tipos clássicos de organização espacial na linha internacional, como descrito na figura 01. A situação número 1 representa o que o autor denomina de "fronteira sem urbanização", quando há maior dispersão da população ou distanciamentos dos núcleos urbanos. O número 2 refere-se às “conurbações binacionais”, que o autor também reconhece como "cidades-gêmeas” ou pares de cidades contíguas. O número 3 são "sistemas urbanos binacionais" formados por cidades que não estão contíguas. O número 4 é denominado "aglomerações binacionais", quando há uma fronteira seca e a expansão da mancha urbana livremente, de ambos os lados. Por último, o número 5, "cidades fronteirizas" que não possuem correspondência no país vizinho. 
O caso de PP/PJC, embora pudesse guardar as características da aglomeração binacional, pela contiguidade, é considerada como uma conurbação binacional ou cidades-gêmeas, porque além da ausência de um acidente geográfico e da expansão da mancha urbana existe potencial de integração econômica e cultural. Nesse caso há uma nítida divisão demonstrada pela paisagem urbana na área mais central, quando a linha internacional é ocupada por um enfileiramento de camelódromos do lado paraguaio e as fachadas, placas e sinalizações dos estabelecimentos comerciais, em espanhol, diferenciam claramente o espaço de transição.

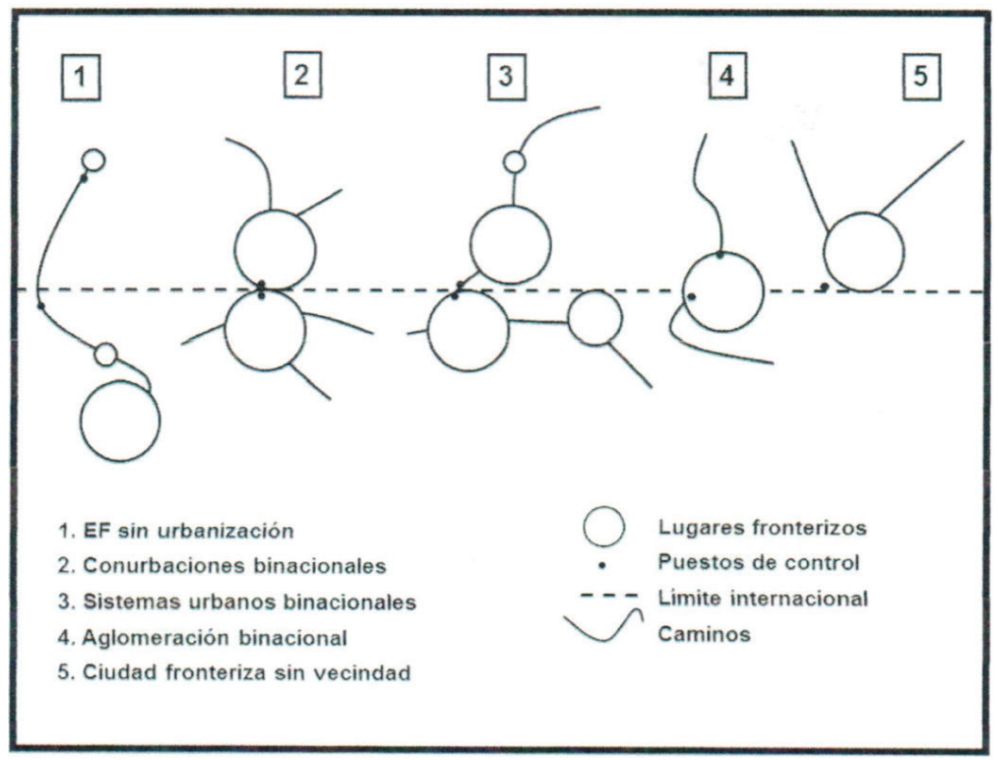

Figura 1 - Lugares de fronteira - padrões de localização ${ }^{4}$ Fonte: Benedetti, 2014.

Para Machado (2005), as cidades-gêmeas são a expressão de um meio geográfico próprio de fronteira, só percebido na escala local/regional, que define como

adensamentos populacionais, cortados pela linha de fronteira, seja esta seca ou fluvial, articulada ou não por obra de infraestrutura, apresentam grande potencial de integração econômica e cultural assim como manifestações localizadas dos problemas característicos 
da fronteira. Aí adquirem maior densidade, com efeitos diretos sobre o desenvolvimento regional e a cidadania. (Machado, 2005, p.261).

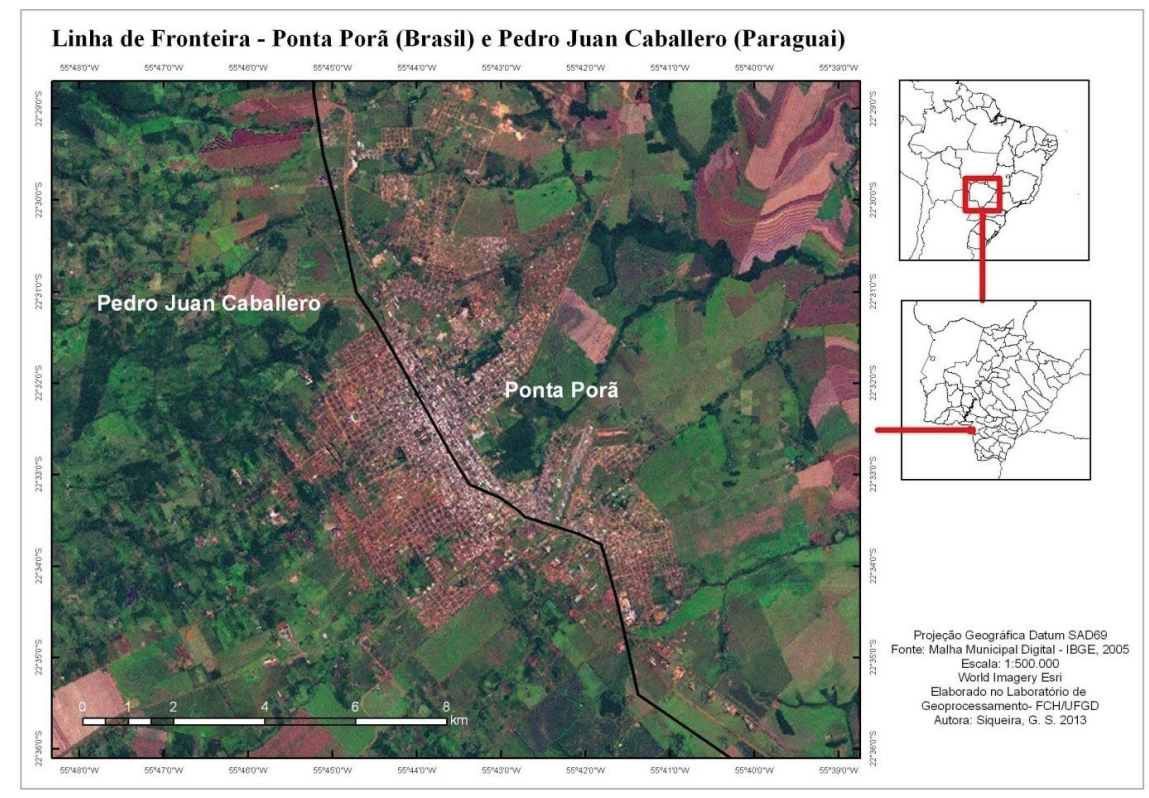

Figura 2 - Linha de Fronteira - Ponta Porã (Brasil) e Pedro Juan Caballero (Paraguai) Fonte: Siqueira (2013).

A concepção de cidades-gêmeas dedica, em nosso entendimento, um protagonismo ao conceito de lugar, que possui estreita relação com a dimensão cultural-simbólica (Souza, 2014). Portanto, essa concepção é de particular significado para as interpretações sobre as relações sociais na fronteira, pois o lugar é dotado de cultura e simbolismo e, na condição de conurbação binacional, também de proximidade física. Ao mencionar a proximidade como uma característica, consideramos "não apenas as relações econômicas que devem ser apreendidas numa análise da situação de vizinhança, mas a totalidade das relações" (Santos, 1996, p.255). A geometria dos metros de distância é repleta de heranças espaciais cujas formas se refuncionalizam pelos usos atuais.

A decisão de onde comprar, na conturbação, não se dá apenas em função de preço, mas também da confiança, por isso o preço, enquanto 
um dado econômico, não é um definidor absoluto. Arriscaríamos afirmar que isso serve até mesmo para os turistas, que buscam informações sobre lojas e fornecedores com seus amigos e conhecidos próximos. A escolha de onde comprar na fronteira, ao pressupor uma relação também para além do preço ou concomitante ao preço, reforça a afirmação de que a fronteira é muito mais que um conceito, é uma experiência (Renoldi, 2015, p.181), experiência essa vivida na materialidade da distribuição e da concentração das casas, dos estabelecimentos comerciais, das vias de acesso, do traçado das ruas. Frase de um consumidor brasiguaia que realizava compras no lado brasileiro ao ser questionado por que fazia compras em determinado estabelecimento "eu venho sempre aqui porque eu já conheço. Minha irmã trabalhou aqui".

Compreendemos a materialidade, representação das relações sociais de um presente e de um passado herdado, ao adotar a noção de "rugosidades" (Santos, 1990). "As rugosidades são o espaço construído, o tempo histórico que se transformou em paisagem, incorporado ao espaço" (Santos, 1990, p.138). O processo de ocupação e povoamento regional foi pautado na exploração da erva mate, no compartilhamento da força-de-trabalho binacional. Mais recentemente, a atividade do mate foi secundarizada pela sobreposição de um turismo de compras vigoroso, que não eliminou a importância do campo enquanto produtor de grãos para exportação (principalmente do lado brasileiro), com o cultivo da soja e a atividade da pecuária bovina. É sintomático da herança produtiva que o principal parque de lazer do município de Ponta Porã tenha a denominação de "Parque dos Ervais", mesmo tendo a erva mate perdido seu protagonismo na economia local.

Paralelo à herança econômica, há a herança histórica muito definida pela Guerra do Paraguai (1864-1870), que teve alguns de seus combates na região, resultando em um novo arranjo econômico e político, somado a uma experiência de subordinação imposta aos paraguaios, talvez ainda não esquecida da memória afetiva. O par “nós/outros" tem muito de uma formação identitária que remonta ao que foi o pós-guerra para os paraguaios e brasiguaios.

Nessa conurbação binacional, como é tradicional em várias cidades de fronteira que possuem trocas comerciais, a variação do dólar é um fator que interfere na complementaridade entre as mesmas. A taxa de câmbio é um vetor da globalização que atinge o local, como uma mediação econômica. Faz parte do senso comum supor que a integração econômica 
seja dependente da situação do câmbio. Embora seja uma condição comprovável, não é suficiente para compreender o grau de integração que é comprometido por uma variação cambial desfavorável. Mais ainda, desfavorável para qual lado da conurbação? A divisão binária pouco contribui para entender o lugar e suas relações sociais. O cotidiano da fronteira em questão está para além da variação do câmbio, em um movimento pendular de perde-ganha-perde que é, em si mesmo, o que mantém a organicidade da fronteira. O protagonismo do lugar e o conteúdo desse conceito que permite compreender a conurbação para além da taxa de câmbio ou quanto vale o dólar no dia.

O município de Ponta Porã está localizado no sudoeste de Mato Grosso do Sul, distante 314 quilômetros da capital Campo Grande e 124 quilômetros do município de Dourados. Importante centro econômico e demográfico no sul do estado, a cidade foi fundada em 1892, com o nome que significa "Ponta Bonita" em Guarani e, posteriormente, recebeu a alcunha de "Princesinha dos Ervais", fato que já denotava a participação da produção e do comércio da erva mate como atividade econômica estruturadora do espaço regional. O nome é indicativo da comunhão de línguas na fronteira, cujos habitantes possuem contato com o espanhol e o guarani, ambas línguas oficiais do Paraguai. A estimativa da população para 2015 é de 86.717 habitantes (IBGE, 2015).

Pedro Juan Caballero foi fundada em 1899. Apresenta um total de 88.189 habitantes (Governo do Paraguai, 2012) e teve no processamento da erva mate a principal atividade econômica de acumulação. É a cidade mais povoada do norte do Paraguai em função do adensamento relativo ao comércio de compras, disponibilidade de serviços e comércio. Destaca-se pela produção de café, exportação de sementes de soja, carne bovina (a pecuária ocupa 54\% da área do Departamento de Amambay) e madeira serrada. Interessante registrar que possui diversas unidades de ensino superior, como Universidade Nacional de Asunción, Universidad Columbia, Universidad Sudamericana e Universidad del Pacífico, muitas com frequência de brasileiros, principalmente nos cursos de medicina. As três avenidas mais próximas da cidade brasileira de Ponta Porã são especializadas no comércio para turistas e, à medida que se adentra e distancia da linha internacional, o cotidiano e as necessidades da população paraguaia tornam-se mais característicos da paisagem formada por moradias e estabelecimentos comerciais nos qual predomina o uso do guarani/espanhol e o guarani como moeda de comércio. 
O regional foi construído com base no processo de acumulação oriundo na atividade extrativa (com protagonismo para a erva mate) e na atividade agropecuária, com proprietários de terras brasileiros também se estabelecendo no Paraguai para a produção de grãos e pecuária extensiva. Estas duas últimas atividades compartilham o espaço com o comércio de fronteira, que atrai um turismo tipificado como turismo de compras no qual se destaca a demanda por eletroeletrônicos, perfumaria, vestuário de grifes importadas, informática e pneumáticos, além de uma infinidade de outros produtos que são característicos de importações da China e leste asiático, com baixo custo de produção. Produtos atrativos quando a conversão da moeda brasileira está valorizada frente ao dólar. O comércio nos estabelecimentos voltados ao turista é cotado em dólar, mas também, como em outras cidades de fronteira, aceita-se o pagamento em reais.

A cotação do dólar tem repercussão na fronteira diretamente no turismo de compras, que faz parte do comércio de reexportação. ${ }^{5} \mathrm{Em}$ janeiro de 2013, a cotação do dólar variou de $\mathrm{R} \$ 2,03$ a $\mathrm{R} \$ 2,05$ para compras no comércio de Pedro Juan Caballero, o que tornava as compras atrativas, principalmente de eletroeletrônicos, informática, pneumáticos (cuja transferência para o Brasil representa "descaminho", quando não recolhidos os impostos). Em outubro de 2015, um dólar chegou a R \$ 4,03 no comércio da fronteira. O dólar em alta reduz o fluxo de turistas, que é um movimento clássico nas conurbações binacionais ou aglomerações fronteiriças.

O dólar não é o fator exclusivo de dinamismo comercial ou maior intercâmbio na conurbação. Há, em PP/PJC, uma dinâmica econômica que se refere ao movimento pendular da própria população residente em ambos os lados, pelo diferencial de preços e também pelas relações de trabalho, com paraguaios se empregando do lado brasileiro e vice-versa.

Nesta pesquisa, priorizamos um olhar para as diferenças no valor do salário mínimo nas cidades pesquisadas para qualificar o movimento comercial na fronteira que não está exclusivamente ligado ao dólar. Esse movimento está relacionado com a vida no lugar, com as heranças espaciais e sociais historicamente estabelecidas, o que pressupõe compartilhamento, reconhecimento, confiança e interação linguística, pois exige compras realizadas em outra língua, com outros códigos culturais. Esse movimento também pressupõe novas estratégias comerciais de marketing, de aceite da moeda estrangeira, de divulgação de preços em duas moedas e da sua 
facilidade de consulta (quando o comércio disponibiliza máquinas de verificação de preço no interior do estabelecimento, que automaticamente fazem a conversão de preço em reais, dólar e guarani). Abordaremos no próximo item, o salário mínimo como mediação da complementaridade na conurbação em questão.

As diferenças no valor do salário mínimo como fator de complementaridade comercial

O movimento de ir e vir em função da cotação da moeda já foi citado nos trabalhos de Coelho e Reis (2011), Adiala (2006), entre outros. A constatação clássica é que o morador da fronteira compra onde lhe convém, valendo-se da diferença de seu poder de compra. Algumas conurbações binacionais de fronteira, como é o caso de $\mathrm{PP} / \mathrm{PJC}^{6}$, além do compartilhamento do comércio pelos turistas, desenvolvem-se uma vigorosa atividade econômica do comércio varejista, tanto no circuito superior quanto inferior da economia urbana (Santos, 2004). O circuito superior é formado pelos estabelecimentos comerciais formais, estruturados física e juridicamente para o acolhimento do turismo de compras (mas não só) que tem um representante importante em Pedro Juan Caballero, que é o Shopping China. ${ }^{7}$ O Shopping está localizado na estrada da cidade de Ponta Porã, do lado paraguaio, com fácil acesso pela rotatória construída pelo empreendimento (Ver Figura 3). Seu estacionamento é monitorado por agentes de segurança privados e circuito interno de câmaras de segurança e a empresa tem a política de oferecer garantia por dias, caso seja detectado problemas de fabricação em seus produtos. Esses dois fatores atendem a um desejo do turista por segurança e garantia.

O circuito inferior possui uma ampla rede de autônomos e empregados informais com a mercadoria apresentada em barracas ao curso da principal avenida de comércio e muitos ambulantes, inclusive menores de idade, demonstrando ofertas de diversos produtos, como pares de meia, acessórios eletrônicos e de informática, medicamentos e, de forma mais discreta, munição para armas de fogo. Ao longo da Av. Dr. Francia (no limite com o Brasil) há uma tentativa de padronização dos estabelecimentos varejistas, mas as mercadorias permanecem expostas, penduradas de forma improvisada, para observação pelos consumidores. (Ver Figura 4) 


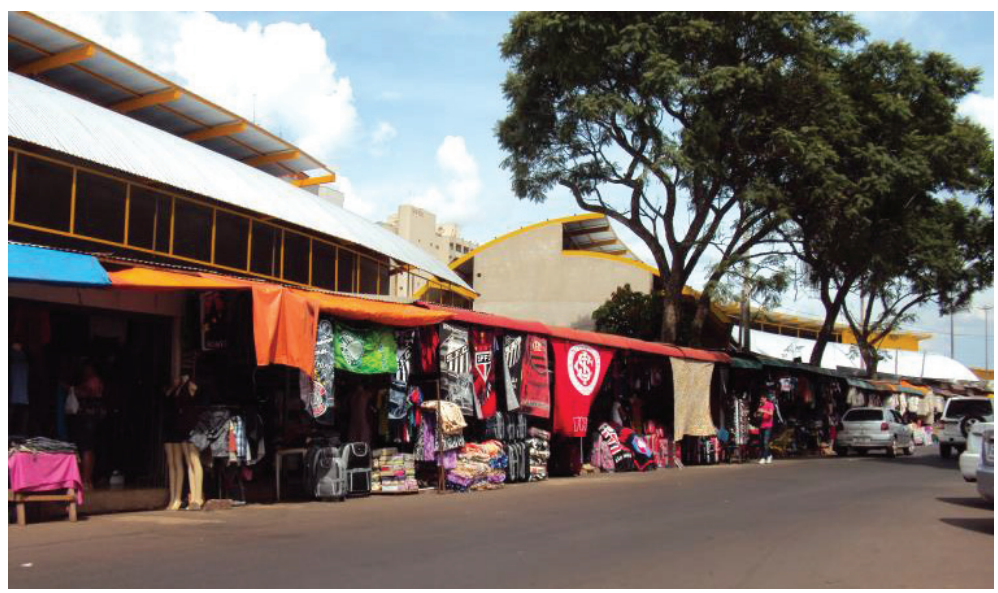

Figura 3 - Vista geral do camelódromo na Av. Dr. Francia - Pedro Juan Caballero, jan., 2013 Fonte: Siqueira (2013).

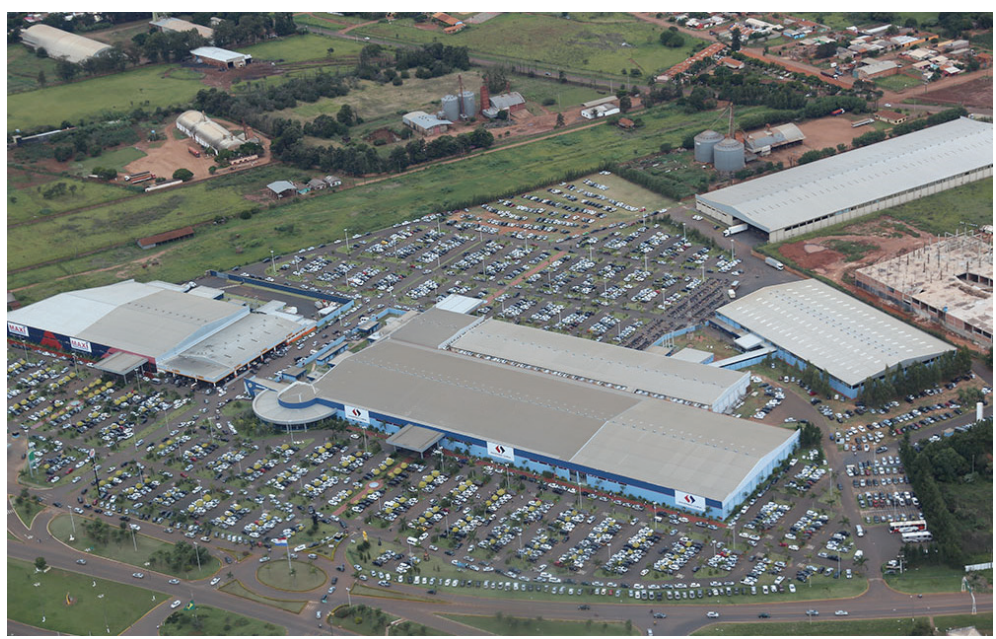

Figura 4 - Vista área do Shopping China, 2015

Fonte: Shopping China - material de divulgação disponível em: < www.shopppingchina.com.py>.

Em 2013 foram tomados com um dólar valendo 2,42 reais e em 2015, com um dólar valendo 4,03 reais. Em janeiro de 2013, um real valia 1.950,00 guaranis e em novembro de 2015, 1 real valia 1.450,00 guaranis (Ver Quadro 1). ${ }^{8}$ 
Quadro 1 - Cotação das moedas praticadas no comércio na conurbação binacional de Ponta Porã e Pedro Juan Caballero

\begin{tabular}{|c|c|}
\hline 20 de janeiro de 2013 & 20 de outubro de 2015 \\
\hline US\$ $1,00=R \$ 2,42$ & US $\$ 1,00=R \$ 4,03$ \\
\hline$R \$ 1,00=$ Gs $1.950,00$ & $R \$ 1,00=G s 1.450,00$ \\
\hline
\end{tabular}

Fonte: Lamoso (2015).

O salário mínimo brasileiro teve um aumento de 16\% entre 2013 e 2015; e o salário mínimo no Paraguai aumentou 10,56\% no mesmo período. Em Ponta Porã, passou de 678 reais para 788 reais de 2013 para 2015. Em Pedro Juan, passou de 1.658.232 guaranis para 1.854.000 guaranis (Ver Quadro 2).

Quadro 2 - Salário mínimo na conurbação binacional de Ponta Porã e Pedro Juan Caballero

\begin{tabular}{|c|c|c|c|c|}
\hline Município & $\mathbf{2 0 1 3}$ & U\$ & $\mathbf{2 0 1 5}$ & U\$ \\
\hline Ponta Porã & R $\$ 678,00$ & 2,03 & R $\$ 788,00$ & 4,03 \\
\hline Pedro Juan Caballero & Gs $1.658 .232,00$ & 0,0005 & Gs $1.854 .000,00$ & 0,007 \\
\hline
\end{tabular}

Fonte: Governo do Paraguai, Ministério do Trabalho (Brasil).

Ao realizarmos a conversão do salário mínimo que é pago em cada lado da fronteira para a cidade vizinha, encontramos uma perda do poder de compra do morador de Ponta Porã, em relação à cidade vizinha, no período de 2013 a 2015. O salário mínimo de Ponta Porã, que valia 1.322.100 guaranis em 2013, passou a valer 1.142.600 guaranis em 2015 . O contrário ocorreu para o trabalhador que recebe seu salário em Pedro Juan, que passou a ter um poder de compra em Ponta Porã de 850,37 reais em 2013 para 1.278,62 reais em 2015. (Ver Quadro 3).

Quadro 3 - Salário mínimo convertido na conurbação binacional de Ponta Porã e Pedro Juan Caballero

\begin{tabular}{|c|c|c|}
\hline Equivalência & $\mathbf{2 0 1 3}$ & $\mathbf{2 0 1 5}$ \\
\hline 1 salário mínimo recebido em Ponta & Correspondia em Pedro Juan & Correspondia em Pedro Juan \\
Porã & Caballero a & Caballero a \\
& Gs $1.322 .142 .600,00$ & 00 \\
\hline 1 salário mínimo recebido em Pedro & Correspondia em Ponta Porã a & Correspondia em Ponta Porã a \\
Juan Caballero & $\mathrm{R} \$ 850,37$ & $\mathrm{R} \$ 1.278,62$ \\
\hline
\end{tabular}

Fonte: Lamoso (2015). 
Essa oscilação do poder de compra é fundamental para compreensão do movimento pendular em ambos os lados da fronteira. Esse movimento não depende do turismo de compras, que é uma dinâmica externa e corrobora para o maior fluxo e expansão das atividades voltadas a atender a demanda dessa clientela em específico. As observações cotidianas e os trabalhos de campo constataram o movimento de clientes paraguaios do lado brasileiro e vice-versa, conforme já extensamente relatado por Lamberti e Oliveira (2008), Lamberti e Martins (2010) e Siqueira (2013). O que os números relativos ao salário mínimo pretendem contribuir é a medida dessa interação, que acontece num movimento pendular conforme o poder aquisitivo.

Não é possível generalizar que haja uma dependência do comércio varejista no sentido de que a população de uma cidade recorra a compras em outro por causa da vantagem comercial. Essa possível vantagem tem que ser significativa e duradoura o suficiente para alterar a opção de compra realizada em seu próprio município de residência, com o conforto da língua nativa, com a disponibilidade das marcas já conhecidas e do reconhecimento e acolhimento do estabelecimento comercial mais utilizado. O que ocorre é que uma parte da população fica mais flexível ao movimento entre um lado e outro da fronteira, "comprando onde convém" (relato de uma moradora de Ponta Porã). Essa fração, que não foi possível estimar percentualmente, consolida a complementaridade e faz uso da diferença de valor das moedas binacionais construindo um movimento pendular que, para os dois momentos (2013 e 2015) tiveram o fluxo demonstrado na Figura 5.

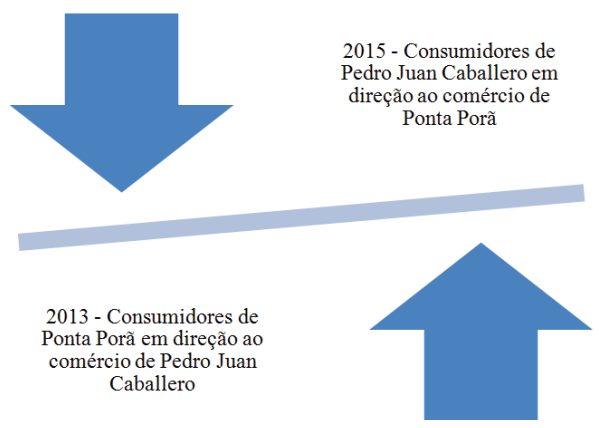

Figura 5 - Esquema do movimento pendular na conurbação PP/PJC

O Quadro 3 demonstra que, em 2013, o salário mínimo brasileiro apresentava maior poder de compra em Pedro Juan que em 2015, fazendo 
com que os brasileiros procurassem com mais frequência as compras do lado paraguaio. Esse movimento inverte-se em 2015, com o salário paraguaio que representava $\mathrm{R} \$$ 850,37 em Ponta Porã em 2013 passando a representar R\$1.278,62 em Ponta Porã em 2015.

Com o intuito de comprovar a oscilação do movimento de compras no comércio varejista, levantamos o preço de alguns produtos de consumo comum pelos habitantes das duas conurbações. Assim, foram elencados os preços dos seguintes produtos: combustíveis, arroz, sabão em pó, óleo de soja, leite e sabonete e calculado o custo para cada habitante, considerando que seu poder de compra é mediado pela cotação da moeda local. Os produtos foram padronizados para marcas e volumes, sendo considerado: 1 litro de gasolina comum, $1 \mathrm{~kg}$ de arroz da marca Zaely, 1 unidade de sabonete da marca Lux (125gr), $1 \mathrm{~kg}$ de sabão em pós da marca Omo, 900ml de óleo de soja da marca Soya, 1 litro de leite integral em embalagem longa vida da marca São Gabriel, 1 garrafa de Coca-Cola (no Brasil a unidade de 2 litros e no Paraguai a unidade de 2,25 litros, que é o padrão utilizado pela empresa engarrafadora), 1 barra de chocolate ao leite de 250 gramas da marca Nestlé - Classic. Os preços foram levantados em um supermercado de bastante movimento no Paraguai e outro no Brasil, respectivamente os supermercados Maxi e Nippon, em janeiro de 2013 e novembro de 2015. O preço dos combustíveis foi tomado no Posto de Gasolina Integral (Pedro Juan) e no Auto Posto Petrobrás Petroshopping (Ponta Porã).

Quadro 4 - Demonstrativo de preços dos produtos em Ponta Porã e em Pedro Juan Caballero em janeiro de 2013 e novembro de 2015 - em R\$

\begin{tabular}{|c|c|c|c|c|}
\hline \multirow{2}{*}{ Produtos* $^{*}$} & \multicolumn{2}{|c|}{$\mathbf{2 0 1 3}$} & \multicolumn{2}{c|}{2015} \\
\cline { 2 - 5 } & Ponta Porã & Pedro Juan Caballero & Ponta Porã & Pedro Juan Caballero \\
\hline 1 litro de gasolina comum & 2,80 & 3,15 & 3,49 & 3,19 \\
\hline 1 kg de arroz & 15,60 & 15,35 & 15,26 & 19,33 \\
\hline 1 unidade de sabonete & 1,71 & 1,73 & 1,75 & 2,13 \\
\hline 900 ml de óleo de soja & 3,20 & 2,97 & 2,99 & 3,27 \\
\hline 1 kg de sabão em pó & 6,60 & 5,99 & 7,88 & 7,41 \\
\hline 1 litro de leite longa vida & 2,35 & 2,10 & 2,99 & 3,14 \\
\hline 2 litros de refrigerante & 4,49 & 4,11 & 5,69 & 6,41 \\
\hline 1 barra de chocolate & 4,18 & 7,28 & 6,20 & 7,13 \\
\hline
\end{tabular}

*Arroz da marca Zaeli, sabonete de 125gramas da marca Lux, óleo de soja da marca Soya, leite longa vida da marca São Gabriel, sabão em pó da marca Omo, refrigerante Coca-cola (com 2 litros no Brasil e 2,25 litros no Paraguai, chocolate ao leite Classic, de 250 gramas da marca Nestlé. 
Os dados, na forma de gráficos, permitem melhor visualização dos processos (Ver Figura 6 e Figura 7). No ano de 2013, apenas a gasolina estava mais barata do lado brasileiro, no posto pesquisado, havendo simetria no preço do sabonete e todos os demais produtos (arroz, óleo de soja, sabão em pó, leite e refrigerante estavam mais baratos em Pedro Juan).

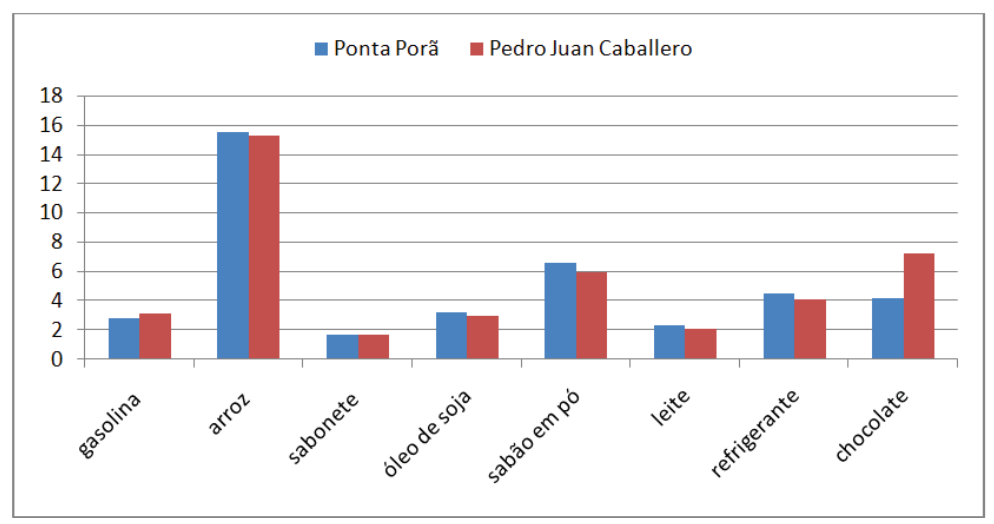

Figura 6 - Comparativo de preços em Reais ( $R \$)$ no ano de 2013

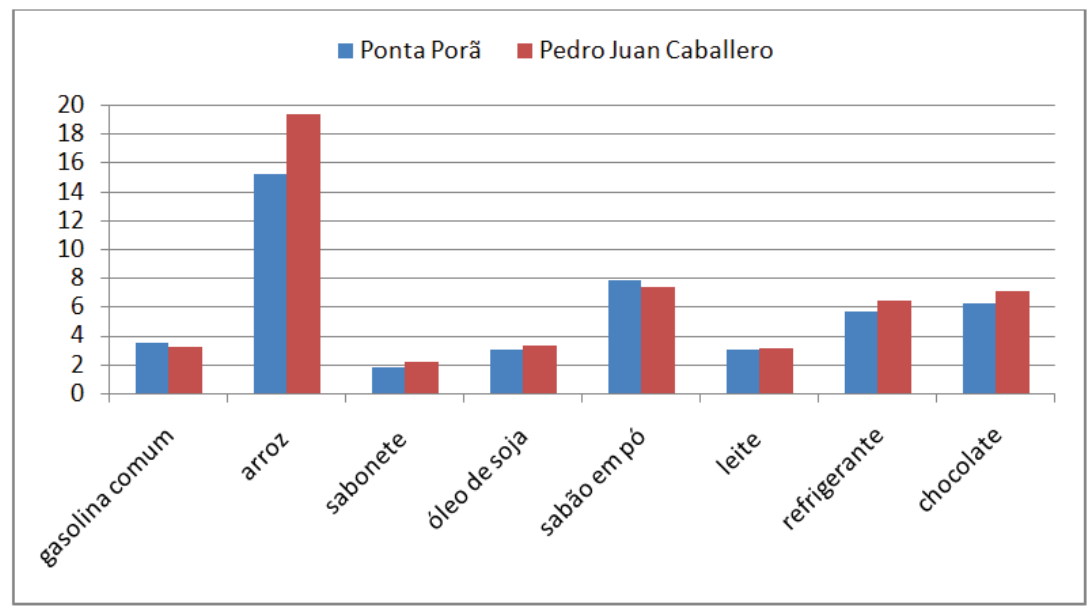

Figura 7 - Comparativo de preços em Reais no ano de 2015 
No ano de 2015, arroz, sabonete, óleo de soja, leite, refrigerante e chocolate estavam mais baratos em Ponta Porã, atraindo consumidores aos supermercados brasileiros. ${ }^{9}$ Dos produtos pesquisados, dois deles possuem maior preferência por marca pelos consumidores paraguaios, o arroz Estrella é produção paraguaia, assim como o leite longa vida Trebol, produzido por uma cooperativa de menonitas no Chaco paraguaio. Isso faz com que, para alguns consumidores, o diferencial de preço, quando não significativo, não justifique a troca de marca de Estrella para Zaeli (arroz) e Trebol para São Gabriel (no caso do leite).

\section{Considerações Finais}

As conurbações binacionais são espaços ricos em possibilidades de interpretações. Nesses espaços, as relações sociais não são mediadas exclusivamente pela diferença de identidade, de língua ou pela cotação da moeda estrangeira. Neste texto, apresentamos a conurbação binacional de Ponta Porã (Mato Grosso do Sul - Brasil) e Pedro Juan Caballero (Departamento de Amambay - Paraguai) sob o olhar da diferença de preços e da equivalência do salário mínimo que é recebido em ambos os lados da conurbação. Discutimos como a complementaridade comercial entre as cidades é construída por usos do comércio varejista, de acordo com a oscilação de preços e salários, questionando a relevância da taxa de câmbio como determinante na economia regional. Pesquisamos o valor do salário mínimo pago nas duas cidades e os preços de um conjunto de produtos oferecidos em dois supermercados e em dois postos de gasolina de cada país em dois momentos distintos, janeiro de 2013 e outubro de 2015. Mesmo considerando que o salário mínimo seja auferido por uma parcela da população e não por todos, tal hipótese reforça, ainda mais, a necessidade de se buscar por menores preços. Identificamos um movimento pendular de melhor preço para os brasileiros comprarem no Paraguai em 2013 e um movimento inverso, de paraguaios em direção ao comércio brasileiro, em outubro de 2015. A taxa de câmbio e a variação do dólar como moeda de compra é decisiva para a participação maior ou menor de turistas brasileiros que se dirigem ao lado paraguaio. No cotidiano da fronteira, entretanto, sua integração e complementaridade tem suporte em relações que se traçam pelos moradores do lugar, brasileiros, paraguaios e brasiguaios. Para isso, compreender a fronteira em suas práticas de fronteirização e o lugar como dimensão simbólica e cultural 
permite transcender a leitura econômica, que credita à taxa de câmbio o determinante da integração.

\section{Agradecimentos}

A autora agradece o auxílio financeiro recebido do CNPq (Chamada Universal 14/2012 - Faixa C) e da Fundect (Edital Chamada Fundect/ CNPq n 06/2011 - PRONEM - Programa de Apoio a Núcleos Emergentes) vigente no período de março de 2012 a dezembro de 2015.

\section{Notas}

1 “Fronteirização” aparece em Grimson (2003) e Albuquerque (2015).

2 "designa o conjunto de objetos e ações que o poder central estabelece, geralmente próximo do limite, mas não necessariamente com a intenção de controlar a acessibilidade. Briones e Del Cairo (2015) exploram a noção de 'práticas de fronteirização', definindo-as como 'as diversas maneiras pelas quais os coletivos sociais marcam um 'dentro e fora', que encontra correspondência na diferenciação nós/os outros." (Tradução nossa).

3 "Processos históricos através dos quais os diversos elementos da fronteira são construídos por poderes centrais e populações locais." (Tradução nossa).

4 Em 2011, Benedetti apresentou esquema semelhante nomeado como "Espaços de frontera: diferentes formas de ocupación". Optamos, entretanto, pela figura apresentada em Benedetti (2014).

5 Sobre o comércio de reexportação, ver Lamberti e Martins (2010).

6 Para mais detalhes sobre os dois circuitos da economia urbana da conurbação PP/PJC, ver Faccin (2015).

7 Empresa fundada em 1933, na cidade de Pedro Juan Caballero que oferece cerca de 210 mil itens importados, variedade de serviços como venda e troca de pneus, abastecimento de combustível, salão de beleza, farmácia, laboratório de revelação de fotografias, praça de alimentação, supermercado e pátio de estacionamento para mais de 3.500 veículos. (Informações fornecidas pela empresa, em outubro de 2015) 
8 Os levantamentos em janeiro de 2013 foram realizados por Gisele dos Santos Siqueira (2013), para a monografia de bacharelado em Geografia intitulada "A complementaridade comercial nas cidades gêmeas de Ponta Porã (Brasil) e Pedro Juan Caballero (Paraguai) e serviram de referência para a replicação do levantamento, realizado em outubro de 2015 por Lamoso, exclusivamente para esse texto.

9 É possível generalizar para "supermercados brasileiros" porque foram consultados, além do supermercado Nippon, os supermercados Grandourados e Bom Gosto, que também apresentaram presença expressiva de consumidores paraguaios realizando suas compras.

\section{Referências}

ADIALA, C. S. M. Efeitos de políticas públicas em cidades de fronteira: Uruguaiana e Sant'Ana do Livramento (RS). Dissertação (Mestrado em Geografia) - Instituto de Geografia. Universidade Federal do Rio de Janeiro, Rio de Janeiro, 2006.

ALBUQUERQUE, J. L. C. Fronteiras múltiplas e paradoxais. Texto \& Debates. Boa Vista, n. 22, p. 71-87, jul./dez., 2012.

. Procesos de fronteirización y sentidos de pertenencia entre Brasil y Paraguai. In: HERNÁNDEZ, A. N.; CAMPOS-DELGADO, A. (Coord.) Líneas, límites y colidancias: mirada a las fronteras desde América Latina.Tijuana: El Colégio de la Frontera Norte, 2015. p. 70-111.

BENEDETTI, A. Espacios fronterizos del sur sudamericano. Propuesta de un modelo conceptual para su estudio. Estudios Fronterizos. v. 15, n. 29, p. 11-47, 2014.

Lugares de frontera y movilidades comerciales en el sur sudamericano: una aproximación multiescalar. In: COSTA, E. A.; COSTA, G. V. L.; OLIVEIRA, M. A. M. (Org.) Fronteira em foco. Campo Grande: UFMS, 2011. p. 32-55.

BENTO, F. R. Cidades-gêmeas e conurbadas de fronteira: na vangarda da integração regional. In: PRADO, H. S. A.; ESPÓSITO NETO, T. (Org.). Fronteiras e relações internacionais. Curitiba: Íthala, 2015. p. 101-114.

BRIONES, C.; DEL CAIRO, C. Prácticas de fronterización, pluralización y diferencia. Universitas Humanística. Bogotá, v. 80, n. 80, p. 13-52, 2015. Disponível em <http://revistas.javeriana.edu.co/index.php/univhumanistica/ article/view/12214/10082>. Acesso em: 05 nov. 2015.

COELHO, K. N. B.; REIS, A. T. L. Espaços urbanos em cidades de fronteira: lógica espacial x lógica legal. In: XIV Encontro Nacional da ANPUR, 2011, Rio de Janeiro. Anais XIV Encontro Nacional da ANPUR. Rio de Janeiro: ANPUR, 2011. Disponível em: <http://www.anpur.org.br>. Acesso em: 15 dez. 2012. 
FACCIN, A. C. T. M. Circuito inferior da economia urbana na atualidade e práticas comerciais na fronteira: circulação de mercadorias e transformações espaciais entre Ponta Porã (MS) e Pedro Juan Caballero (PY). Boletim Gaúcho de Geografia, v. 42, n. 2, p. 455-474, maio, 2015.

GOVERNO DO PARAGUAI. Dirección General de Estatísticas, Encuentas y Censos, 2012. Disponível em:<http://www.dgeec.gov.py>. Acesso em: 05 nov. 2015.

GRIMSON, A. La nación en sus límites: contrabandistas y exilados en la frontera Argentina-Brasil. Buenos Aires: Gedisa, 2003.

IBGE (INSTITUTO BRASILEIRO DE GEOGRAFIA E ESTATÍSTICA). Diretoria de Pesquisas - DPE - Coordenação de população e indicadores sociais COPIS. 2014. Disponível em: <http://www.cidades.ibge.gov.br/xtras/perfil.php?lang=\& codmun $=500660 \&$ search $=$ mato-grosso-do-sul|ponta-pora $>$. Acesso em: 28 out. 2015

LAMBERTI, E.; MARTINS, P. C. S. M. Reexportação e turismo de compras na fronteira. Pelotas: UFPel, 2010.

LAMBERTI, E.; OLIVEIRA, T. C. M. As trocas, a territorialidade e o ambiente na fronteira Ponta Porã (Brasil) e Pedro Juan Caballero (Paraguai). In: Seminário Internacional sobre a América Platina, 1., 2006, Campo Grande. América Platina: textos escolhidos. Campo Grande: UFMS, 2008. v. 1, p. 75 - 97. CD-ROM.

LAMOSO, L. P. Trabalho de campo realizado em Pedro Juan Caballero e Ponta Porã. 2015.

MACHADO, L. O; HAESBAERT, R.; RIBEIRO, L.; STEIMAN, R.; PEITER, P.; NOVAES, A. O Desenvolvimento da faixa de fronteira: Uma proposta conceitualmetodológica. In: OLIVEIRA, T. C. M. de (Org.). Território sem limites: estudos sobre fronteiras. Campo Grande: UFMS, 2005. p. 51-76. Disponível em: <www. retis.igeo.ufrj.br>. Acesso em: 18 fev. 2013.

Estado, territorialidade, redes. Cidades gêmeas na zona de fronteira sul-americana. In: M. L. S. (Org.). Continente em chamas. Globalização e território na América Latina. 1.ed. Rio de Janeiro: Civilização Brasileira, 2005, v. 1, p. 243-284.

MINISTÉRIO DA INTEGRAÇÃO REGIONAL. Portaria $\mathrm{n}^{\circ} 125$, de 21 de março de 2014. Estabelece o conceito de cidades-gêmeas nacionais, os critérios adotados para essa definição e lista todas as cidades brasileiras por estado que se enquadram nesta condição. Brasília, DF: Diário Oficial, 24 mar. 2014.

RENOLDI, B. Movimiento de fronteira: esperiencias cotidianas de habitar y transitar en los límites de Argentina, Brasil y Paraguay. In: HERNÁNDEZ, A. H.; CAMPOS-DELGADO, A. (Coord.) Líneas, límites y colidancias: mirada a las fronteras desde América Latina. Tijuana: El Colégio de la Frontera Norte, 2015. p.175-199.

SANTOS, M. A natureza do espaço - técnica e tempo, razão e emoção. São Paulo: Hucitec, 1996.

Paulo: Edusp, 2004.

O espaço dividido: os dois circuitos da economia urbana.São 
SIQUEIRA, G. S.A complementaridade comercial nas cidades gêmeas de Ponta Porã (Brasil) e Pedro Juan Caballero (Paraguai). Monografia (Bacharelado em Geografia) - Universidade Federal da Grande Dourados, Dourados, 2013.

SOUZA, M. L. de. Os conceitos fundamentais da pesquisa sócio-espacial. Rio de Janeiro: Bertrand, 2014.

Lisandra Pereira Lamoso - Possui Graduação em Geografia pela Universidade Estadual Paulista de Presidente Prudente. Mestrado em Desenvolvimento Regional pela mesma instituição. Doutorado em Geografia Humana pela Universidade de São Paulo. Pós-doutorado pelo Instituto de Geografia da Universidade Federal do Rio de Janeiro. Atualmente é Professora Associada IV na Universidade Federal da Grande Dourados (UFGD).

Recebido para publicação em 15 de dezembro 2015 Aceito para publicação em 10 de janeiro de 2016 